\title{
College Adjustment Issues and Life Satisfaction amongst Students Living with Family and Out-Station Students in Delhi
}

\author{
Poonam Phogat* and Kateni Katy Rajina \\ Gargi College, Delhi University, Delhi, India \\ Email of corresponding author: phogat109@gmail.com
}

\begin{abstract}
Every student passing out from high school and transiting to college requires some kind of adjustment, which may be big or small. Some may especially have more challenges to deal along with stresses of a new environment i.e. college. College freshman are confronted with challenges starting from living apart from parents and friends in the case of some students (here the outstation), adjusting to the academic unit, taking daily-life responsibilities, and developing a new set of social relationships with peers and faculty (Henton, Lamke, Murphy, \& Haynes, 1980). This study aims to assess the college adjustment issues and its correlation with life satisfaction among students living with family and outstation students in Delhi. A null hypothesis was proposed that there would be no significant difference between students living with family and outstation students in terms of college adjustment issues. It was also hypothesized that there would be a negative correlation between life satisfaction and college adjustment issues for both the groups. The sample size selected was 74 from Delhi in the age range of 18-25 years where 36 were students living with family and 38 were outstation students. College Adjustment Scale (CAS,Anton \& Reed, 1991) and Satisfaction with Life Scale (Diener et.al, 1985) were used to collect data. The result indicates that there was significant difference on different dimensions of college adjustment for students living with parents in Delhi and outstation students. College adjustment issues were found to be negatively-correlated with life satisfaction in college students.
\end{abstract}

Keywords: Adjustment; Life Satisfaction; College Students; Out-Station; Family.

\section{INTRODUCTION}

Adjustment is something we hear of very often and simply means change. It is the behavioral process through which we maintain a balance among various needs and the hurdles of the environment, making changes to fit into something and the process of adapting or becoming used to a new or unfamiliar situation. According to Oxford dictionary, adjustment is 'a small alteration or movement made to achieve a desired fit, appearance, or result.' Simply, it is the correction or modification of certain ideas, beliefs and behaviors to suit to a new change.

Humans by nature strive to be in a constant zone of comfort to meet their psychological needs such as love, or affirmation from people surrounding them which is why social adjustments are said to be similar to physiological adjustments. When needs arise, they urge for interpersonal activity to satisfy those needs especially in a new environment which increases their familiarity and comfort, and expect or believe that their needs will be met in the future. As such, adjustment process may involve the following parts: (a) a strong and persistent need or motive (b) failure to fulfill the need, (c) varied activity, or exploratory behavior and (d) factors that will degrade or put off the previous stimulus to complete the adjustment.

Adjustment Issues in college: College adjustment is a transition stage. It is the detachment level of a student's life experiences with the prevalence of new norms, values and expectations of the college (Bennett and Okinaka, 1990). Parental attachment and favorable family structure for college development are the factors concerned for this passage of transition (Lopez, Campbell, \& Watkins, 1988). Kenny (1987) described the transition to college as a naturally occurring "strange situation" and that the securely attached adolescent is able to manage the separation reactions and the adjustment challenges brought about by the college environment. All students require some sort of adjustment as they join college and varies depending on the background, experience, and prior schooling. Chickering and Schlossberg (1995) pointed out that college students living away from family tend to experience the most dramatic adjustment and that, those students who are still living at home and commutes daily to college would experience slightly less change. 
A positive relationship between parental attachment and measures of well-being in late adolescents has been shown through recent research including adjustment to college (Armsden \& Greenberg, 1987; Kenny \& Donaldson, 1992; Kobak \& Sceery, 1988). Adding to this, research evidence shows both parental attachment and separation-individuation are important for college adjustment (Bluestein, Walbridge, Friedlander, \& Palladino, 1991; Rice, FitzGerald, Whaley, \& Gibbs, 1995). There are limited researches, which show the quality of relationships in college as a strong measure of well being. Social skills together with perceived social support, predicted certain aspects of college adjustment (Riggio, Watring and Throckmorton, 1993) while Zea, Jarama and Bianchi (1995) reported perceived social support and psychosocial competence as significant predictors. The transition from high school to college is also considered a culture shock which involves remarkable social and psychological relearning of various ideas, values, beliefs and opportunities which are to be imbibed in the zone of new friends and teachers (Pascarella and Terenzini, 1991). Interestingly, this culture shock is particularly awful for those students not having siblings or parents who attended college.

Life satisfaction: Life satisfaction is an overall feeling of contentment towards life. It could be a sense of accomplishment and achieving goals in life at a particular point of time, and is a feel good factor. High satisfaction in life would be positive while lower satisfaction with life's outcome would result negatively. According to Scheufele and Shah (2000) life satisfaction and other measures of quality of life reflect a general evaluation of one's surroundings, an evaluation, which may be positive or negative.

Diener, et al., (1985) equate life satisfaction with subjective happiness or personal contentment. While Kahneman \& Krueger, (2006) also highlighted that individuals' life satisfaction is determined, in part, by their social ties. Ratings of happiness made by one's friends (Leary \& Kowalski, 1990), a sociable and extraverted personality, frequent interpersonal communications that have positive affect (Diener, Sandvik \& Payot, 1991), and happiness of one's family members all are correlated to high life satisfaction and happiness. Life satisfaction is one of the most well-established indicators of general wellness and, moreover, positive functioning. (Suldo, Riley, Shaffer, 2006)

Relation of College Adjustment issues and life satisfaction: A study done by Chow (2005) on university students' life satisfaction with respect to degree of satisfaction of various aspects of life found that students were most satisfied with relationship with mother, siblings and close friends, living environment and arrangement. It also revealed that students from higher socioeconomic status were more satisfied with their academic experiences, self-esteem, relationship with significant other and living conditions. Pilcher (1998) examined how life satisfaction in college students is predicted by affect and daily events and found that an increase in subjective satisfaction was predicted by decreases in depression, negative affect, frequency of illness and increase in vigor. The results indicated that judgments of life satisfaction, as measured by the Satisfaction With Life Scale (SWLS), were significantly predicted by affect and daily events. Suldo, Riley and Shaffer, (2006) have examined the extent to which a few categories of school-related factors such as the school climate, intelligence and ability grouping at school, academic achievement and overall appraisals of one's happiness with academics are correlated with students' life satisfaction. A study also showed that academic performance was positively related to satisfaction with life among college students (Samaha and Hawi, 2016).

Present study

The present study aimed to assess the various college adjustment issues faced by the students living with family and outstation students in Delhi from the age range of 18-25 years.

Hypotheses:

1. A null hypothesis was proposed that there would be no significant difference between students living with family and outstation students in terms of college adjustment issues.

2. There would be a negative correlation between life satisfaction and college adjustment issues for both the groups. 


\section{METHOD}

\section{Participants}

In the present study, there were total 74 participants from the age group of 18-25 years living in Delhi. Out of this 36 (N1) participants were students living with family while 38 (N2) participants were outstation students. The participants took part in the study after giving their voluntary consent and no incentives were given for their participation. Participants were asked to fill in the online survey honestly. The participants were recruited using purposive sampling.

\section{Design}

The study followed an ex-post facto quantitative research design. Ex-post facto research is done when an event has already occurred and the researcher wants to know more of the 'what and how' of the event. Measures used were standardized questionnaires and data was subjected to quantitative analysis. Quantitative methods emphasize objective measurements and the statistical, mathematical, or numerical analysis of data collected through polls, questionnaires, and surveys, or by manipulating pre-existing statistical data using computational techniques. It focuses on gathering numerical data and generalizing it across groups of people or to explain a particular phenomenon. Exploratory research, as the name implies, intends merely to explore the research questions and does not intend to offer final and conclusive solutions to existing problems.

\section{Tools Used}

College Adjustment Scale (CAS; Anton, \& Reed; 1991). Adjustment to college was assessed by College Adjustment Scale (CAS) of 108 items, which was developed by William D. Anton and James R. Reed in 1991. The nine dimensions of CAS are: anxiety (AN), depression (DP), suicidal ideation (SI), substance abuse (SA), self-esteem Problems (SE), interpersonal problems (IP), family problems (FP), academic problems (AP) and career problems $(\mathrm{CP})$. The CAS is intended primarily for students ages 17-30. Internal consistency reliability coefficients for the 9 scales range from .80-.92 with a mean of .86. Five studies examined the convergent and discriminant validity and its ability to distinguish students in counseling from those not in counseling. Results support the validity of the CAS as a measure of college adjustment problems.

Satisfaction With Life Scale (SWLS; Diener, Emmon, Larsen, \& Griffin; 1985). The life satisfaction of college students was assessed by Satisfaction With Life Scale (SWLS), which was developed in 1985 by Diener, Emmons, Larsen and Griffin. It is a short 5-item instrument designed to measure global cognitive judgments of satisfaction with one's life and is made up of just 5 items. The SWLS is shown to be a valid and reliable measure of life satisfaction, suited for use with a wide range of age groups and applications, which makes possible the savings of interview time and resources compared to many measures of life satisfaction.

\section{Procedure}

The online Google forms were prepared for both the scales; College Adjustment Scale (CAS) and Satisfaction With Life Scale (SWLS). Participants were contacted via online measures and over phone. The consent from the participants was taken and those who consented voluntarily they were sent the Google forms. The completed response forms were automatically returned to the researcher's mail. These were scored as per the scoring technique of each scale respectively and recorded in the excel sheet. Finally, the data was prepared for analysis.

\section{Data Analysis}

The data was subjected to quantitative analysis. First, the descriptive statistics were calculated. The mean and standard deviation (sd) were obtained to know about the shape of the distribution. This was followed by use of parametric statistics i.e. the ttest was used to check for significant differences between the two groups. Also correlation was calculated to look for relation between the dimensions of CAS and the Satisfaction With Life Scale. 


\section{RESULTS}

Table 1: Mean and SD for Dimensions of CAS and SWLS of Students Living with Family (SWF) and Outstation Students

\begin{tabular}{|lcccc|}
\hline & \multicolumn{2}{c}{ (SWF) N=36 } & \multicolumn{2}{c|}{ Outstation students $\mathbf{N}=\mathbf{3 8}$} \\
Variables Dimensions & M & SD & M & SD \\
AP & 27.194 & 6.682 & 27.605 & 6.434 \\
AN & 27.583 & 9.560 & 26.736 & 8.857 \\
IP & 25.583 & 7.558 & 25.236 & 8.037 \\
DP & 24.833 & 9.426 & 23.684 & 8.108 \\
CP & 27.861 & 8.822 & 25.131 & 9.090 \\
SI & 21.111 & 10.375 & 17.105 & 6.862 \\
SA & 15.805 & 7.248 & 16.421 & 6.811 \\
SE & 28.416 & 7.239 & 28.473 & 6.016 \\
FP & 23.027 & 7.765 & 21.789 & 6.194 \\
Total CAS & 221.4167 & 63.4473 & 212.184 & 52.808 \\
Total SWLS & 21.16667 & 7.994641 & 23.23684 & 7.32797 \\
\hline
\end{tabular}

Table 2: T-Value of CAS and SWLS between Students with Parents and Outstation Students

\begin{tabular}{|lllllllllll|}
\hline AP & AN & IP & DP & CP & SI & SA & SE & FP & Total CAS & Total SWLS \\
-0.27 & 0.39 & 0.19 & 0.56 & 1.29 & 1.94 & -0.37 & -0.04 & 0.75 & 0.68 & -1.16 \\
\hline
\end{tabular}

No significant difference was found for all the dimensions of CAS at both levels of significance as the tvalue at 0.005 was 2.648 and 1.994 at 0.025 level. There was also no significant difference for total CAS and total SWLS.

Table 3: Correlation between CAS and SWLS of Students with Family and Outstation Students

\begin{tabular}{|lll|}
\hline CAS (Dimension) & Students with Family (SWLS) & Out-station students (SWLS) \\
AP & $-0.666^{* *}$ & $-0.272(\mathrm{NS})$ \\
AN & $-0.527 * *$ & $-0.374 *$ \\
IP & $-0.538^{* *}$ & $-0.423 * *$ \\
DP & $-0.589 * *$ & $-0.431^{* *}$ \\
CP & $-0.489 * *$ & $-0.363 *$ \\
SI & $-0.545^{* *}$ & $-0.137(\mathrm{NS})$ \\
SA & $-0.276(\mathrm{NS})$ & $-0.226(\mathrm{NS})$ \\
SE & $-0.592^{*} *$ & $-0.667 * *$ \\
FP & $-0.487 * *$ & $-0.244(\mathrm{NS})$ \\
\hline
\end{tabular}

The table shows the correlation between each dimension of CAS and SWLS. Substance abuse for students living with parents was not significant which may mean that there is a weak correlation with life satisfaction. However, academic problem and suicidal ideations were also not significant for outstation students.

Table 4: Total Correlation of CAS and Satisfaction with Life Scale (SWLS)

\begin{tabular}{|ll|}
\hline Pearson's $\mathbf{0 . 5 2 3} * *$ \\
\hline
\end{tabular}

The correlation (r) of CAS and SWLS was -0.523 which was greater than the values at both levels of significance; 0.302 at 0.01 level and 0.232 at 0.05 level. 


\section{DISCUSSION}

The aim of the study was to assess the college adjustment issues and the life satisfaction of students living with family and the outstation students in Delhi. The total number of participants was 74 (36 students living with family \& 38 outstation students). The study followed an ex-post facto quantitative research design.

The total mean and SD of students living with family was 221.41 and 63.44 while it was 212.18 and 52.80 for outstation students. The mean of all the dimensions of the CAS for the students with family was average except for suicidal ideation and substance abuse. The mean for suicidal ideation was 21.11 and the SD was 10.37 which was above average and towards the higher end while the mean and SD for substance abuse for students with family was 15.80 and 7.24 which lies below average and was towards the lower end. Scores on the suicide ideation (SI) scale was inclined more towards the higher end, which indicates that the students living with family are likely to have thoughts and ideas of suicide and may view suicide as an attainable or suitable solution to their problems. It is very likely that they may also have formulated a suicide plan or may have attempted suicide in the past. Hirsch and Ellis (1995) suggested that suicidal behaviors may occur due to a complex interaction between social factors and childhood care. The influence of living in a singleparent home may also contribute to whether or not a person considers suicide. Harris and Molock (2001) found that having strong family support was associated with fewer experiences of suicide ideation and depression. Scores on the substance abuse (SA) came out to be below average which may mean that students living with family are not too much involved into substance use or even if they do, it may be at a minimal level and hence, the affect on the students is not too much. Longitudinal data show that, while in high school, students who go on to attend college have lower rates of heavy drinking than do those who will not attend college. The mean and SD of all the dimensions of CAS for outstation students were average and only substance abuse was below average and lies towards the lower end.

The mean and SD for students living with family in the satisfaction with life scale was 21.16 and 7.99 and the mean and SD for outstation students was 23.23 and 7.32. This indicates that both the group that is; students living with family and outstation students are slightly satisfied with life. Lent et.al., (2009) stated that academic adjustment was predictive of students' global life satisfaction. However, students are often more satisfied with the diversity of opportunities for college student life on large campuses (Astin, 1993).

The total t-value of CAS for students with family and the outstation students was 0.68 but no significant difference were found for any of the dimensions at both the level of significance as the $\mathrm{t}$-value at 0.005 level was 2.648 and 1.994 at 0.025 . Similarly, the total t-value for SWLS was -1.16 and was not found to be significant. This could mean that students living with family have as many issues as compared to outstation students and that there is no difference in their adjustment issues. A study by Mahanta and Aggarwal (2013) revealed that higher the levels of perceived social support from family and friends, higher the life satisfaction.

The correlation of CAS and SWLS for the students living with family came out to be significant for all the dimensions at 0.01 level except for substance abuse which was not significant at both the levels as the correlation value at were 0.418 and 0.325 . This could mean that substance use does not determine life satisfaction in college students. This also means that there is a high correlation of all of these dimensions of college adjustment to life satisfaction. For the outstation students, the correlation of CAS and SWLS of 3 dimensions: interpersonal problems, depression and self-esteem problems came out to be significant at 0.01 level (0.418), indicating high dependence on these dimensions for life satisfaction. A study indicates that incidents of depression and suicide are prevalent on college campuses and that there are a number of specific causes of depression, suicidal ideation, and suicidal behavior. While anxiety (AN) and career problems (CP) came out to be significant at 0.05 level (0.325). The dimensions where correlation was not significant for outstation students were academic problems (AP), suicidal ideation (SI), substance abuse (SA) and family problems (FP) at both the level of significance. This could mean that students staying away from family do not consider academic problems or suicidal ideation as measures of life satisfaction. 
According to Josselson (1988), staying away or living independently as a student requires a reworking of family relationships so that the independence of the adolescent does not come at the expense of close familial ties. Family theorists argue that a certain degree of distance from the family orbit is necessary for the adolescent to develop as an emotionally and functionally independent person (Bowen, 1976). Research also indicates that students may be better adjusted when they maintain independence, but also maintain a supportive relationship with parents (Anderson and Fleming, 1986). This may be one reason why the distance from home and managing things as an outstation student were not significant indicators of adjustment. Maintaining quality student-parent relationships as well as adequate personal autonomy are more influential in the transition process. In another study done by Rani and Midha (2014), results suggested that there are moderately low levels of resilience and average level of life satisfaction among teenagers in the contemporary Indian society and that there is a significant positive correlation between resilience and life satisfaction of the teenagers. Dwivedi and Rastogi (2017) also found proactive coping as a single significant predictor of life satisfaction among emerging adults.

The total correlation of CAS and SWLS came out to be -0.523 , which means that there is a significant negative correlation between adjustment and life satisfaction. When the adjustment issues in college increases it has an impact on their satisfaction. Also, when there are less problems in college life, it results in better adjustment and greater satisfaction. The life satisfaction of a college student would increase when they are in sync with the demands in college and find a balance in all the dimensions of the College Adjustment scale.

\section{CONCLUSION}

The results of this study suggest that measures of college adjustment issues and life satisfaction vary for students living with parents and outstation students. The two variables are significantly correlated which means that the dimensions of the college adjustment scale are all factors contributing to college student's life satisfaction. The findings of the study is inclined towards the explanation that when a college student have more of adjustment issues in college it will impact the kind of quality or satisfaction they will have on life as a whole. Hence, the increase in college adjustment issues decreases the life satisfaction level of a college student as both the variables came out to be negatively correlated. However, the adjustment issues for a student living with family may differ from an outstation student and their satisfaction may also vary accordingly. The adjustment issues faced by the students with family may not be viewed much as an issue for the outstation student as they have their own social constructs and problems, they also adhere to. Similarly, for students living with parents, there are certain values and expectations from family and some sort of constant pressure which adds to their adjustment issues in college. There is no difference in satisfaction level between the two groups but there is a difference in their adjustment style, which leads to a conclusion that both the hypothesis of this study has been accepted and thus indicates that both the groups are slightly satisfied with life. Mooney, Sherman \& Lo Presto (1991) stated 'it is not the actual distance from home that impacts adjustment but the perception of the distance being "just right" and is in support that students are better adjusted when they maintain residential and economic independence, but also maintain a supportive relationship with parents (Anderson and Fleming, 1986).

Despite the finding, there were some limitations to this study, which includes the small sample size, the big gap in the sample size of male and female participants and time-constraint. The unequal number of male and female participants contributed to gender disparity and with limited time allotted, it was not possible to collect a large sample size. The small sample size may have lacked the statistical power to detect all withingroup differences. Participants were only Delhi college students, hence they were not necessarily representative of the entire college students population. Authenticity of response may be absent as the data collection was done through google form. The results depend on the honesty of the participants, which cannot be guaranteed, as the test was taken online. The standardized test used for this study were developed abroad which may also lead to the possibility of some cultural differences and may have contributed to the findings of the present study. 


\section{Future Recommendation}

As the findings of the study indicates that irrespective of students living with family or students not living with family, they face some issues in terms of college adjustment. To some, these issues create serious problems due to individual differences which leads to suicidal ideation or substance abuse irrespective of whether the students live with family or not. As a precautionary measure, colleges should provide counseling for the students to better cope with these issues, which come along, especially in the first year of college due to the major transition from high-school environment to full independence in the college level. Future researchers should also consider the limitations of the present study and assess the other possible causes of adjustment issues of college students and how students can enhance better life satisfaction as they were found to be negatively correlated.

\section{REFERENCES}

[1] Anderson, S. A., and Fleming, W. M. (1986). Late adolescents' home-leaving strategies: Predicting ego identity and college adjustment. Adolescence, 21(82), 453-459.

[2] Anton, W.D. \& Reed, J.R. (1991). College Adjustment Scale (CAS). Psychological Assessment.

[3] Armsden, G.C. \& Greenberg, M.T. (1987). The inventory of parent and peer attachment: Individual differences and their relationship to psychological well-being in adolescence. Journal of Youth and Adolescence, Vol 16, 427-454. https://doi.org/10.1007/bf02202939

[4] Astin, A.W. (1993). Diversity and Multiculturalism on the campus: How are students affected? Change: The magazine of higher learning. 25(2), 44-49. https://doi.org/10.1080/00091383.1993.9940617

[5] Bennett, C. \& Okinaka, A.M. (1990). Factors related to persistence among Asian, Black, Hispanic, and White undergraduates at a predominantly white university: Comparison between first and fourth year cohorts. The Urban Review. 22, 33-60. https://doi.org/10.1007/bf01110631

[6] Blustein, D. L., Walbridge, M. M., Friedlander, M. L., \& Palladino, D. E. (1991). Contributions of psychological separation and parental attachment to the career development process. Journal of Counseling Psychology, 38(1), 39-50. https://doi.org/10.1037/0022-0167.38.1.39

[7] Chickering, W., and Schlossberg, K. (1995). Getting the Most out of College. Needham Heights, MA: Allyn and Bacon.

[8] Chow,H.P.H., (2005). Life Satisfaction among University Students in a Canadian Prairie City: a Multivariate Analysis, 70(2), 139-150. https://doi.org/10.1007/s11205-004-7526-0

[9] Diener, E., Emmons, R. A., Larsen, R. J., \& Griffin, S. (1985). The Satisfaction with Life Scale. Journal of Personality Assessment, 49, 71-75. https://doi.org/10.1207/s15327752jpa4901_13

[10] Diener, E., Sandvik, E., \& Pavot, W. (1991). Happiness is the frequency, not the intensity, of positive versus negative affect. In F.Strack, M.Argyle, \& N.Schwarz (Eds.), Subjective well-being: An interdisciplinary perspective (pp. 119-139). Oxford, England: Pergamon Press. https://doi.org/10.1007/978-90-481-2354-4_10

[11] Dwivedi, A. \& Rastogi, R. (2017). Proactive Coping, Time Perspective and Life Satisfaction: A Study on Emerging Adulthood. Journal of Health Management, 19(2), $264-274$. https://doi.org/10.1177/0972063417699689

[12] Harris, T. L., \& Molock, S. D. (2000). Cultural orientation, family cohesion, and family support in suicide ideation and depression among African American college students. Suicide and Life-Threatening Behavior, 30(4), 341-353.

[13] Hirsch, J. and Ellis, J.B (1995). Family Support and Other Social Factors Precipitating Suicidal Ideation. International Journal of Social Psychiatry, 41(1), 26-30. https://doi.org/10.1177/002076409504100103

[14] Holmbeck, G. N., \& Wandrei, M. L. (1993). Individual and relational predictors of adjustment in first-year college students. Journal of Counseling Psychology, 40(1), 73-78. https://doi.org/10.1037/0022-0167.40.1.73

[15] Jenkins, S.R, Belanger, A., Connally, M.L, Boals, A., and Duron, K.M., (2013). First-Generation Undergraduate Students' Social Support, Depression, and Life Satisfaction. Retrieved from https://doi.org/10.1002/j.21611882.2013.00032.x

[16] Kahneman, D. \& Krueger, A.B. (2006). Developments in the measure of subjective well being. Journal of Economic Perspectives, 20(1), 3-24. https://doi.org/10.1257/089533006776526030

[17] Kenny, M. E. (1987). The extent and function of parental attachment among first-year college students. Journal of Youth and Adolescence, 16, 17-27. https://doi.org/10.1007/bf02141544 
[18] Kenny, M. E., \& Donaldson, G. A. (1992). The relationship of parental attachment and psychological separation to the adjustment of first-year college women. Journal of College Student Development, 33(5), 431-438.

[19] Lapsley, D. K., Rice, K. G., \& Shadid, G. E. (1989). Psychological separation and adjustment to college. Journal of Counseling Psychology, 36, 286-294. https://doi.org/10.1037/0022-0167.36.3.286

[20] Leary, M. R., \& Kowalski, R. M. (1990). Impression management: A literature review and two-component

[21] model. Psychological Bulletin, 107(1), 34-47. https://doi.org/10.1037/0033-2909.107.1.34

[22] Lent, R.W, Taveira, M.C, Sheu, H.B and Singley, D (2009).Social cognitive predictors of academic adjustment and life satisfaction in Portuguese college students: A longitudinal analysis: Journal of Vocational Behavior, 74(2), 190-198. https://doi.org/10.1016/j.jvb.2008.12.006

[23] Lopez, F. G., Campbell, V. L., \& Watkins, C. E. (1988). Family structure, psychological separation, and college adjustment: A canonical analysis and cross-validation. Journal of Counseling Psychology, 35(4), 402-409. https://doi.org/10.1037/0022-0167.35.4.402

[24] Mahanta, D. \& Aggarwal,M. (2013). Effects of Perceived Social Support on Life Satisfaction of University students. European Academic Research, Vol 1 (6).

[25] Mooney, S.P., Sherman, M.F. \& Lo Presto, C.T. (1991). Academic Locus of Control, Self-Esteem, and Perceived Distance from Home as Predictors of College Adjustment. Journal of Counseling and Development, 69(5), 445448. https://doi.org/10.1002/j.1556-6676.1991.tb01542.x

[26] Pascarella, E.T., and Terenzini, P.T., (1991). How College Affects Students. San Francisco: Jossey-Bass. https://doi.org/10.15288/jsas.2002.s14.23

[27] Pilcher.J.J, (1998). Affective and Daily Event Predictors of Life Satisfaction in College Students. Social Indicators Research, 43(3), 291-306. https://doi.org/10.1023/a:1006883231707

[28] Rani, R. \& Midha, P. (2014). Does Resilience Enhance Life Satisfaction among Teenagers? IOSR Journal of Humanities and Social Science. https://doi.org/10.9790/0837-19671619

[29] Rice, K.G., Fitzgerald, D.P., Whaley, T.J. \& Gibbs, C.L. (1995). Cross-Sectional and Longitudinal Examination of Attachment, Separation-Individuation, and College Student Adjustment. Journal of Counseling \& Development, 73(4), 463-474. https://doi.org/10.1002/j.1556-6676.1995.tb01781.x

[30] Riggio, R.E., Watring, K.P. \& Throckmorton, B. (1993). Social skills, social support and Psychosocial Adjustment. Personality and Individual Differences. 15(3), 275-280. https://doi.org/10.1016/0191$\underline{8869(93) 90217-q}$

[31] Samaha, M. and Hawi, N.S (2016). Relationships among smartphone addiction, academic performance, and satisfaction with life. Computers in Human Behavior, 57, 321-325. https://doi.org/10.1016/j.chb.2015.12.045

[32] Scheufele, D.A. \& Shah, D.V. (2000). Personality Strength and Social Capital: The Role of Dispositional and Informational Variables in the Production of Civic Participation. Sage Journals. 27(2), 107-131. https://doi.org/10.1177/009365000027002001

[33] Suldo, S. M, Riley, K.N., and Shaffer, E.J (2006). Academic Correlates of Children and Adolescents' Life Satisfaction. Sage Journals, 27(5), 567-582. https://doi.org/10.1177/0143034306073411

[34] Zea, M.C., Jarama, S.L. \& Bianchi, F.T. (1995). Social support and psychosocial competence: Explaining the adaptation to college of ethnically diverse students. American Journal of Community Psychology. 23, 509-531. https://doi.org/10.1007/bf02506966

[35] Josselson, R. (1988). The Embedded self: I and Thou Revisited. Self, ego and identity. 91-106. https://doi.org/10.1007/978-1-4615-7834-5 5

[36] https://en.oxforddictionaries.com/definition/adjustment

[37] https://www.britannica.com/science/adjustment-psychology

Received on 02-10-2020

Accepted on 07-10-2020

Published on 27-10-2020

(C) 2020 Poonam Phogat and Kateni Katy Rajina; Licensee ATSK Publishers.

This is an open access article licensed under the terms of the Creative Commons Attribution Non-Commercial License (http://creativecommons.org/licenses/by-nc/3.0/) which permits unrestricted, noncommercial use, distribution and reproduction in any medium, provided the work is properly cited. 